\title{
On the bright side: The influence of brightness on overall taste intensity perception
}

Citation for published version (APA):

van der Heijden, K., Festjens, A., \& Goukens, C. (2021). On the bright side: The influence of brightness on overall taste intensity perception. Food Quality and Preference, 88, [104099].

https://doi.org/10.1016/j.foodqual.2020.104099

Document status and date:

Published: 01/03/2021

DOI:

10.1016/j.foodqual.2020.104099

Document Version:

Publisher's PDF, also known as Version of record

Document license:

Taverne

\section{Please check the document version of this publication:}

- A submitted manuscript is the version of the article upon submission and before peer-review. There can be important differences between the submitted version and the official published version of record.

People interested in the research are advised to contact the author for the final version of the publication, or visit the DOI to the publisher's website.

- The final author version and the galley proof are versions of the publication after peer review.

- The final published version features the final layout of the paper including the volume, issue and page numbers.

Link to publication

\footnotetext{
General rights rights.

- You may freely distribute the URL identifying the publication in the public portal. please follow below link for the End User Agreement:

www.umlib.nl/taverne-license

Take down policy

If you believe that this document breaches copyright please contact us at:

repository@maastrichtuniversity.nl

providing details and we will investigate your claim.
}

Copyright and moral rights for the publications made accessible in the public portal are retained by the authors and/or other copyright owners and it is a condition of accessing publications that users recognise and abide by the legal requirements associated with these

- Users may download and print one copy of any publication from the public portal for the purpose of private study or research.

- You may not further distribute the material or use it for any profit-making activity or commercial gain

If the publication is distributed under the terms of Article $25 \mathrm{fa}$ of the Dutch Copyright Act, indicated by the "Taverne" license above, 


\title{
Short Communication
}

\section{On the bright side: The influence of brightness on overall taste intensity perception}

\author{
Kimberley van der Heijden ", Anouk Festjens, Caroline Goukens \\ Department of Marketing and Supply Chain Management, Maastricht University School of Business and Economics, The Netherlands
}

\section{A R T I C L E I N F O}

\section{Keywords:}

Ambient brightness

Overall taste intensity perception

Field setting

Cross-modal interaction

\begin{abstract}
A B S T R A C T
Ambient light luminance (i.e., brightness or dimness) is a frequently used tool by managers to enhance the overall ambience in their restaurants. The current research explores how a change in a restaurant's ambient brightness influences the overall taste intensity perception of the food that is being served there. We conducted a between-group experiment in a field setting (i.e., a fine-dining restaurant), where we manipulated the illuminance level of the ambient light (dim vs. bright). Guests were served a dish-tailored to our research question-and asked to evaluate its overall taste intensity. The results demonstrate that guests exposed to the bright ambient light perceived the overall taste of the dish as more intense as opposed to guests exposed to the dim ambient light. The results thus show that modifying the ambient illuminance level in a restaurant does not only affect the overall ambience but also changes the overall taste experience of the food being served. This finding is not only theoretically relevant for research on multisensory integration, but it also provides tools for taste modulation, and - as such—for strategies to decrease salt and sugar consumption among diners.
\end{abstract}

\section{Introduction}

Remember the last time you went out for a fine-dining experience. Chances are high that you entered a restaurant where soft music was playing in the background and lights were dimmed, urging you to sit back and enjoy the upcoming experience. Restaurant managers are well aware of the powerful effects of ambient stimuli (e.g., lightening, music, or scent; for a review see Krishna, 2012) and gratefully use them to improve the overall ambience in restaurants to enhance consumers' dining experiences (Biswas et al., 2017). In fact, of the wide range of ambient stimuli at their disposal, managers frequently use ambient light luminance (brightness or dimness) because they can control this factor relatively easily and with minimal monetary investment (Biswas et al., 2017).

The effect of illuminance on the consumption experience is an important topic of research. While some studies focused on the impact of changing the hue of lighting (e.g., Spence, Velasco, \& Knoeferle, 2014), several other studies have examined how the level of illuminance (i.e., brightness or dimness) affects food preferences and intake (e.g., Biswas et al., 2017; Bschaden et al., 2020; Gal, Wheeler, \& Shiv, 2007; Xu \& Labroo, 2014). For example, it was found that ambient brightness increases people's desire for spicier (Xu \& Labroo, 2014) and healthier
(Biswas et al., 2017) food. Likewise, it was reported that consumers with a preference for strong coffee tend to drink more coffee under bright than under dim lights, and that the opposite holds for consumers with a preference for mild coffee (Gal et al., 2007).

Yet, less is known on how illuminance affects consumers' overall taste intensity perception of their food choices. Still, many factors (e.g., liking) that affect one's food intake originate from perceptions of overall taste intensity (Vickers, Holton, \& Wang, 2001). As such, overall taste intensity perception is a more rudimentary dependent measure than food preference and consumption, and insights on how illumance affects it are-from a theoretical perspective-important if we want to fully understand how consumers' dining experiences are impacted by the brightness or dimness of a restaurant. Furthermore, investigating how luminance impacts perceptions of overall taste intensity is not only theoretically relevant, but it also provides tools for taste modulation, and-as such—for strategies to decrease salt and sugar consumption among diners.

The aim of the current research is thus to investigate whether exposure to a specific level of illuminance (i.e., brightness or dimness) influences the overall taste intensity perception of a food item. Specifically, we organized an experiment in a field setting (i.e., a fine-dining restaurant) where we manipulated light luminance and tested how it

\footnotetext{
* Corresponding author at: Maastricht University School of Business and Economics, Tongersestraat 53 6211LM Maastricht, The Netherlands.

E-mail address: kcw.vanderheijden@maastrichtuniversity.nl (K. van der Heijden).
} 
affected the overall taste intensity perception of the food served there. Note that when we refer to overall taste, we refer to the everyday notion of overall taste (meaning flavour), and thus not to gustation.

There are a few other articles that investigated how illuminance influences the sensory attributes of food. Some work, for example, looked at how illuminance affects the taste thresholds of basic tastes. Katsuura et al. (2005) found that higher levels of illuminance increased taste sensitivity for sweet and bitter tastes. Similarly, Srivastava et al. (2013) demonstrated that increased levels of illuminance lowered the taste recognition threshold for sweet foods.

Other research focused on the impact of illuminance on basic taste intensity perceptions (i.e., saltiness in Bschaden et al., 2020, study 1; sweetness, saltiness and sourness in Rebollar et al., 2017; see also Wilson $\&$ Gregson, 1967 for other early research in this area). However, this line of research led to mixed results. For example, Rebollar et al. (2017) asked participants to sample a sweetened natural yoghurt in both a bright versus dimly lit tasting room, and to rate its level of sweetness. They found that participants rated the yoghurt as sweeter under bright (vs. dim) levels of illuminance. In contrast, Bschaden et al. (2020) asked participants to sample a tomato soup on two separate days under different illuminance conditions (bright vs. dim) and-amongst other variables-to evaluate a number of basic tastes (i.e., sweetness, saltiness, and sourness). Their results showed that the tomato soup was perceived as saltier under low (vs. high) levels of illuminance, yet they reported no effects of illuminance level on sourness and sweetness. As such, their findings are not consistent with the findings by Rebollar et al. (2017), Katsuura et al. (2005), and Srivastava et al. (2013). Furthermore they also failed to replicate this finding in a second study (where they adapted the environment and illuminance levels).

In contrast to earlier work-which mainly focused on the taste intensity of one or a few basic taste attributes in isolation-the current research investigates whether exposure to a specific level of illuminance influences the overall taste intensity perception of a food item. Note that the typical dishes that we eat for lunch or dinner typically consist of a blend of different tastes and we virtually never experience pure basic tastes in isolation. For the current study, we therefore created a food item tailored for our particular research question-a dish consisting of a balance of basic tastes (i.e., sweet, salt, bitter and sour)—and asked participants to rate the overall taste intensity of this food item. Note that we did not include umami as a taste in the experiment as it has the property to boost some of the other basic tastes, and thus potentially impact the taste composition (Suwankanit et al. 2013).

Furthermore, to optimize the ecological validity of our findings, we ran this study in a field setting (i.e., restaurant)—in contrast to previous research which has mainly been conducted in controlled laboratory settings (Bschaden et al., 2020; Gregson, 1964; Katsuura et al., 2005; Rebollar et al., 2017; Srivastava et al., 2013; Wilson \& Gregson, 1967).
Since we know from prior research that the specifics of a study setting can impact food-related measures (García-Segovia et al., 2015), we opted to conduct this study in a fine-dining restaurant.

Lastly, and contrary to previous studies investigating the effect of illuminance on overall taste intensity perception, we decided for a between-group design. The latter allowed us to avoid any learning effects over the course of the study, which might have confounded previous studies. In the remainder of this article, we will explain our experimental design and our findings. We end with a discussion of our findings, limitations, and suggestions for future research.

\section{Method}

\subsection{Place}

To test if the overall taste of a complex dish is perceived as being more intense under bright (vs. dim) lighting conditions, we conducted a field experiment at a fine-dining restaurant. See Fig. 1 for an impression of the restaurant. The study took place in late Autumn on weeknights and the weekend (i.e., Thursday through Saturday) during the dinner service (6:00 PM to 11:00 PM). This setup ensured that the level of daylight and the number of guests was relatively constant on the different experimental days.

\subsection{Participants}

Participants were one-hundred-fifty-two guests who visited the restaurant during our experiment. A power analysis (power $=80 \% ; \alpha=$ 0.05), using saltiness perception in Bschaden et al. (2020, study 1 ) as primary dependent variable, indicated a required number of participants of 128 participants. So this number $(n=152)$ allowed for a dropout rate of $15 \%$. Fourteen guests did not agree to participate in the study, leaving a final sample of one-hundred-thirty-eight (49.3\% female, Mage $=50.53$ years).

\subsection{Illuminance manipulation}

A common measure for illumination is the amount of lux (Areni \& Kim, 1994). A lux can be described as the luminous flux of one lumen produced per square meter. In our experiment, we manipulated the light intensity by adapting the illuminance levels of the pendant lamps (warm white light, $55 \mathrm{~W}$ ) above each table. In the dim ambient light condition, the illuminance was set at $13 \mathrm{~lx}$ and in the bright ambient light condition, the light luminance was set at $300 \mathrm{~lx}$. These luminance levels were the same as in previous research (i.e., Bschaden et al., 2020; Biswas et al., 2017). Depending on the day that the guests were visiting the restaurant, they were assigned to either the dim or the bright ambient
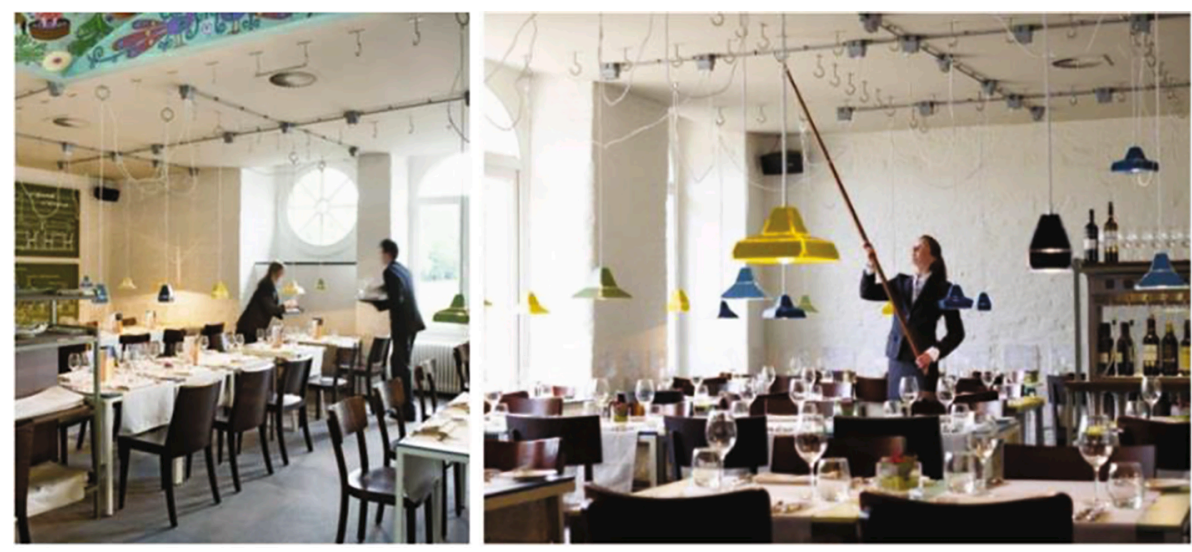

Fig. 1. Impression of the restaurant in daylight. 
light condition. To compare, the ambient light illuminance amounts 500 $\mathrm{lx}$ in a typical office setting (National Science Foundation) and daylight is $10.000 \mathrm{~lx}$.

\subsection{Procedure}

Upon entering the restaurant, a waiter (i.e., a research assistant) welcomed the guest and guided him or her to one of the tables. As is common in this restaurant, every guest received the same 4-course menu. After the guest took a seat and ordered a drink, the waiter immediately served him or her the first course. She explained that this dish was a new addition to the menu, and that the chefs therefore would like to get some feedback. After receiving consent from the guests, the waiter distributed a short questionnaire (i.e., flipped to ensure that the questions were not immediately visible) and asked the guests to taste the dish prior to turning the page and completing it.

Important is that the chefs especially composed this dish-an amuse-to allow for an optimal test of the current research question. It thus contained the four basic tastes (i.e., salt, sour, sweet, and bitter) and consisted of multiple textures (e.g., crispy and creamy elements) while being as balanced as possible. The dish could be consumed within two or three bites, and was developed such that there would be a minimal chance of triggering an allergic reaction. Fig. 2 shows a picture of the dish as well as a list of its ingredients.

After consuming the dish, the guests rated the perceived overall taste intensity of the dish (on a 9-point Likert scale ranging from $1=$ 'not intense' to 9 = 'extremely intense'), and its perceived pleasantness (on a 6-point Likert scale ranging from $1=$ 'extremely unpleasant' to $6=$ 'extremely pleasant'). Next, the guests rated the level of the ambient illuminance (i.e., manipulation check; rated on a 9-point Likert scale ranging from $1=$ 'not intense' to $9=$ 'extremely intense'), and its perceived pleasantness (on a 6-point Likert scale ranging from $1=$ 'extremely unpleasant' to 6 = 'extremely pleasant').

Next, as the brightness level might also influence the perceived intensity of other sensory modalities (Krishna, 2012; Walsh, 2003), guests also rated the perceived intensity of the ambient sounds that were present in the restaurant during their tasting of the dish (i.e., 'How do you perceive the intensity of the sound in the room?'), the ambient aromas (i.e., 'How do you perceive the intensity of the smell in the room?'), and the ambient tactile stimuli (i.e., 'How do you perceive the intensity of the touch with the cutlery?'); all on 9-point Likert scales ranging from 1 $=$ 'not intense' to $9=$ 'extremely intense'. We made sure that all stimuli of the other sensory modalities were kept constant over the different experimental days-i.e., similar room scents, same cutlery, identical music volume (55 dB), and similar music track list.

Finally, guests indicated which of the basic tastes (i.e., sweet, salt, sour, bitter, or none) they perceived to be dominant while tasting the (balanced) dish. Once the guest completed their questionnaire, the waiter collected it and thanked him or her for the participation.

\section{Results}

The results of the manipulation check showed that the bright ambient light condition was perceived as more intense in terms of the level of illuminance as opposed to the dim ambient light condition (Mbrightlight $=6.26, \mathrm{SD}=1.56$ vs. Mdimlight $=4.68, \mathrm{SD}=1.69 ; F$ $(1,133)=31.710, p<.001, \eta 2=0.193)$. Moreover, the illuminance level was perceived as equally pleasant in both the bright and dim ambient light condition (Mbrightlight $=4.66, \mathrm{SD}=0.77$ vs. Mdimlight $=$ 4.69, $\mathrm{SD}=1.08 ; F(1,132)=0.034, p=.854, \eta 2=0.000)$.

An ANOVA with light intensity as the independent variable and overall taste intensity as the dependent variable revealed a main effect of the level of light intensity $(F(1,136)=18.227, p<.001, \eta 2=0.118)$. Specifically, guests in the bright ambient light condition rated the overall taste as more intense (Mbrightlight $=7.12, \mathrm{SD}=1.11$ ) as opposed to guests in the dim ambient light condition (Mdimlight $=6.43, \mathrm{SD}=$ 0.74).

A second ANOVA revealed that light intensity had no effect on the pleasantness of the perceived overall taste intensity (Mbrightlight $=5.12$, $\mathrm{SD}=0.73$ vs. Mdimlight $=5.13, \mathrm{SD}=0.82 ; F(1,131)=0.010, p=.922$, $\eta 2=0.000$ ). Recall that we also asked guests which of the four basic tastes they considered to be dominant. We found that $43.2 \%$ did not consider any of the tastes to be dominant, followed by $6.8 \%$ who considered the sweet taste to be dominant, $14.4 \%$ the salty taste, $13.6 \%$ the bitter taste, and $22 \%$ the sour taste $(4.3 \%$ did not fill out the question). Thus, consistent with our theorizing, there seems to be a balance of basic tastes in the dish we used.

Furthermore, we also tested the effect of light intensity on the perceived intensity of other sensory modalities, and found an enhancing effect of light illuminance on the perceived intensity of the auditory and olfactory stimuli (sound: Mdimlight $=4.81, \mathrm{SD}=2.05$ vs. Mbrightight $=$ $5.70, \mathrm{SD}=1.86 ; F(1,133)=7.006, p=.009, \eta 2=0.050$; scent: Mdimlight $=4.37, \mathrm{SD}=2.12$ vs. Mbrightight $=5.07, \mathrm{SD}=2.00 ; F(1,134)$ $=4.008, p=.047, \eta 2=0.029$ ), but not on the perceived intensity of haptic stimuli (Mdimlight $=5.37, \mathrm{SD}=1.65$ vs. Mbrightlight $=5.67, \mathrm{SD}=$ $1.91 ; F(1,128)=0.883, p=.349, \eta 2=0.007)$.

\section{Discussion}

The aim of the present work was to test how the level of ambient brightness or dimness of a restaurant influences one's overall taste intensity perception. We tested this research question in a field setting,

Ingredients:
- Soy dressing
- Red grapefruit (3 small pieces)
- Orange (3 small picces)
- Little, marinated mushrooms (3 pieces)
- Miso mayonnaise
- Goat chcesc (20 grams per platc)
- Potato starch and a mixture to fry
- Salad pea on top

Fig. 2. Ingredient list and amuse.

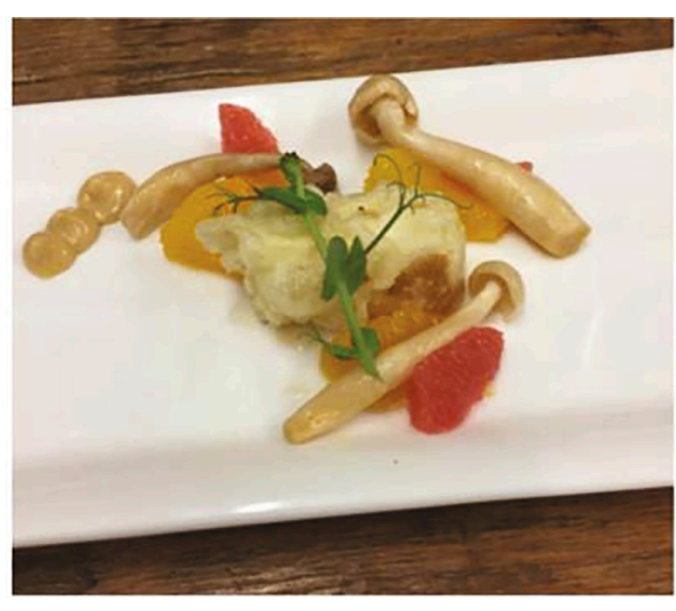


namely a fine-dining restaurant. The results show that guests dining in a brightly lit restaurant perceive the overall taste of a dish-created for the purpose of the study - to be more intense than guests dining in a dimly lit restaurant.

\subsection{Link to previous literature}

Our findings are consistent with prior research demonstrating lower taste thresholds of sweet and salty foods (Katsuura et al., 2005; Srivastava et al., 2013) and increased taste intensity perception of sweet food (Rebollar et al., 2017) in brightly (vs. dimly) lit environments. Nevertheless, our findings seem inconsistent with one of the studies (i.e., study 1 ) in the article of Bschaden et al. (2020) who reported that people perceive a soup as saltier under low as opposed to bright illuminance. Yet, they failed to replicate their results in a second study. Moreover, Bschaden et al. (2020, study 1) reported that their participants considered the dim light condition as less pleasant than the bright light condition. As pleasantness ratings and intensity judgements are found to be closely related (Veldhuizen, van Rooden, \& Kroeze, 2006), this latter result may have impacted their results. In the current research, we did not find a significant difference in the perceived pleasantness of the two illuminance conditions, nor did we find a difference in the pleasantness of the overall taste intensity perception. As such, our results cannot be explained by any differences in experienced pleasantness.

\subsection{Potential explanations}

We realize that the field setting of this study did not allow us to fully control the restaurant environment, and thus isolate the mechanism. Yet, our findings are consistent with some earlier work in this research area.

The neuroscientific framework "A Theory Of Magnitude (ATOM)", for example, suggests a common neural mechanism for representing magnitude between pairs of prothetic (i.e., magnitude-based) dimensions (Walsh, 2003). It assumes a correlation between magnitudes in different domains - that is, bigger and brighter in one domain should correlate with bigger and brighter in another domain. As such, this theory predicts that higher intensities of a specific stimulus in one modality (e.g., visual domain) triggers higher intensity perceptions of a stimulus in another modality (e.g., gustatory domain).

In a similar vein, previous research has found that exposure to bright (vs. dim) light increases mental awareness (Biswas et al., 2017) and intensifies initial affective reactions (Xu \& Labroo, 2014). Also, Gal et al. (2007) put forward the concept of cross-modal associations, where the perception of a stimulus in one modality (i.e., light intensity) may be mentally associated with the perception of a stimulus in another modality (i.e., taste intensity).

Furthermore, it could also be the case that the above described effects result from indirect parallel processes. For example, illuminance level could have indirectly influenced the overall taste intensity perception by changing the perceived appearance of the food (e.g., Piqueras-Fiszman et al., 2012) or by changing the perceived level of ambient noise (Spence et al., 2019). As we measured perceived ambient noise in our survey, we were able to test this last alternative explanation. We conducted a mediation analysis with level of illuminance as independent variable, perceived level of sound intensity as mediator and perceived intensity of overall taste as dependent variable. This analysis yields an insignificant indirect effect of perceived level of sound intensity (indirect effect: $\mathrm{B}=0.0096, \mathrm{SE}=0.0460,95 \%$ CI $[-0.0830$, 0.1087]; Model 4, Hayes, 2018). As such, we conclude that perceived level of ambient noise cannot explain guests' difference in overall taste intensity perceptions.

Additionally, to account for possible effects on food appearance, we
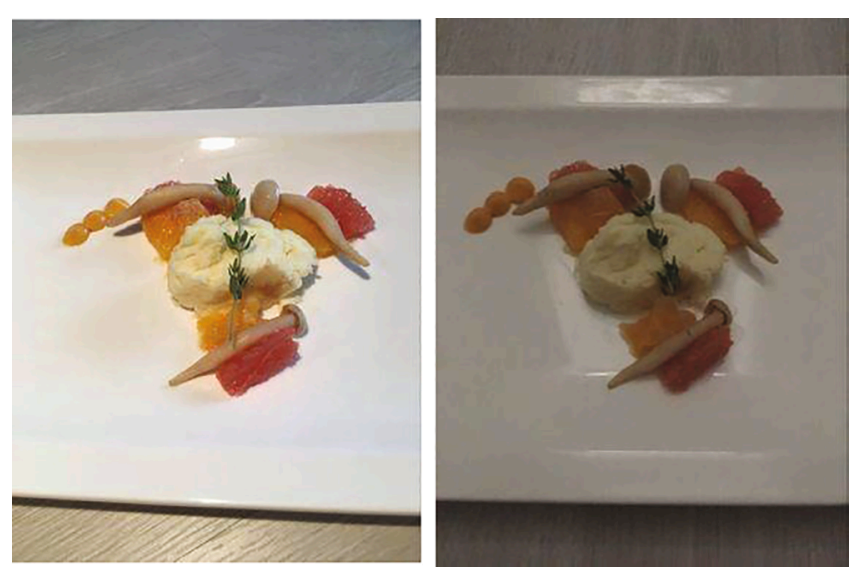

Fig. 3. Stimuli control study (bright vs. dim condition).

ran a small online control study $(\mathrm{N}=100,62.7 \%$ female, Mage, $=36.27$ years). In this study, we asked participants to rate a picture of the dish taken under either a bright or a dim light (see Fig. 3 for the pictures). Specifically, we asked participants to rate the expected overall taste (i.e., 'How would you expect the taste of the dish to be?') and expected overall taste intensity (i.e. 'How would you expect the flavour intensity of the dish to be?') both on 9 point Likert scales. The results reveal an insignificant effect for both expected overall taste $(\mathrm{F}(1,98)=0.371, \mathrm{p}=$ $0.544, \eta 2=0.004)$ as well as expected overall taste intensity $(\mathrm{F}(1,98)=$ 1.709, $\mathrm{p}=0.194, \eta 2=0.017)$. These findings cast doubt on the possibility that the observed effects result from changes in the appearance of the food.

To conclude, there remain a number of possible theories which could-partially_explain the documented effect. We hope that our research will serve as an inspiration for future research to look into the above-mentioned theories within this specific study context.

\section{Contributions}

This article has both theoretical and practical implications. With regards to the former, the present research was conducted in an ecologically valid setting (i.e., a fine-dining restaurant) under natural conditions and therefore answers the question that was put forward by Bschaden et al. (2020) on whether light intensity-as a sole ambient factor-is able to impact sensory perception outside an artificial setting.

Furthermore, our study contributes to the increasing stream of research on multisensory store experiences (for a review see Krishna 2012), which aims at understanding how different sensory inputs interact with each other in retail settings. Our study adds to this stream of research by demonstrating that a change in a stimulus related to one sense can enhance the perception of a stimulus represented in another modality.

From a managerial perspective, our study provides interesting insights. In many restaurants, illuminance can be controlled with relative ease and minimal monetary investment (Biswas et al., 2017), yet illuminance is mainly used to create a nice ambience. Our findings suggest that changing the illuminance in a restaurant-at the same time-also changes the taste experience of the food consumed in the restaurant. The latter might offer some tactics to reduce the use of flavour enhancers, and as such indirectly contribute to the health of restaurant diners. In a similar vein, supermarkets-who often provide food samples to their customers-may benefit from bright ambient lighting. The present research suggests that brighter lit environments increase the overall taste intensity perception of the food being sampled. 


\section{CRediT authorship contribution statement}

Kimberley van der Heijden: Conceptualization, Methodology, Formal analysis, Visualization, Writing - original draft, Writing - review \& editing, Validation. Anouk Festjens: Conceptualization, Methodology, Writing - original draft, Writing - review \& editing, Supervision. Caroline Goukens: Conceptualization, Methodology, Writing - original draft, Writing - review \& editing, Supervision, Funding acquisition.

\section{Declaration of Competing Interest}

The authors declare that they have no known competing financial interests or personal relationships that could have appeared to influence the work reported in this paper.

\section{Acknowledgements}

The authors thank Inge Lodewijkx for her assistance in running the field study. Financial support from the Netherlands Organization for Scientific Research (016.VIDI.185.075) is gratefully acknowledged.

\section{References}

Areni, C. S., \& Kim, D. (1994). The influence of in-store lighting on consumers' examination of merchandise in a wine store. International Journal of Research in Marketing, 11(2), 117-125. https://doi.org/10.1016/0167-8116(94)90023-X

Biswas, D., Szocs, C., Chacko, R., \& Wansink, B. (2017). Shining light on atmospherics: How ambient light influences food choice. Journal of Marketing Research, 54(1), 111-123. https://doi.org/10.1509/jmr.14.0115

Bschaden, A., Dörsam, A. F., Cvetko, K., Kalamala, T., \& Stroebele-Benschop, N. (2020). The impact of lighting and table linen as ambient factors on meal intake and taste perception. Food Quality and Preference, 79, 1-8. https://doi.org/10.1016/j. foodqual.2019.103797

Gal, D., Wheeler, S. C., \& Shiv, B. (2007). Cross-modal influences on gustatory perception. Retrieved from. http://papers.ssrn.com/sol3/papers.cfm?abstrac $\mathrm{t}$ id $=1030197$.

Garcia-Segovia, P., Harrington, R. J., \& Seo, H.-S. (2015). Influences of table setting and eating location on food acceptance and intake. Food Quality and Preference, 39(1), 1-7. https://doi.org/10.1016/j.foodqual.2014.06.004
Gregson, R. A. M. (1964). Modification of perceived relative intensities of acid tastes by ambient illumination changes. Australian Journal of Psychology, 16(3), 190-199. https://doi.org/10.1080/00049536408255517

Hayes, A. F. (2018). An introduction to mediation, moderation, and conditional process analysis, Second edition: A regression-based approach. New York: Guilford publications.

Katsuura, T., Jin, X., Baba, Y., Shimomura, Y., \& Iwanaga, K. (2005). Effects of Color Temperature of Illumination on Physiological Functions. J. Physiol. Anthropol., 24(4), 321-325. https://doi.org/10.2114/jpa.24.321

Krishna, A. (2012). An integrative review of sensory marketing: Engaging the senses to affect perception, judgment and behavior. Journal of Consumer Psychology, 22(3), 332-351. https://doi.org/10.1016/j.jcps.2011.08.003

Piqueras-Fiszman, B., Alcaide, J., Roura, E., \& Spence, C. (2012). Is it the plate or is it the food? Assessing the influence of the color (black or white) and shape of the plate on the perception of the food placed on it. Food Quality and Preference, 24(1), 205-208. https://doi.org/10.1016/j.foodqual.2011.08.011

Rebollar, R., Lidón, I., Guzmán, R., Gil, I., \& Martín, J. (2017). The influence of illuminance level on perception and willingness to buy during the tasting of sweetened natural yoghurt. Food Quality and Preference, 62, 270-274. https://doi. org/10.1016/j.foodqual.2017.05.007

Spence, C., Reinoso-Carvalho, F., Velasco, C., \& Wang, Q. J. (2019). Extrinsic auditory contributions to food perception \& consumer behaviour: An interdisciplinary review. Multisensory Research, 32, 275-318. https://doi.org/10.1163/22134808-20191403

Spence, C., Velasco, C., \& Knoeferle, K. (2014). A large sample study on the influence of the multisensory environment on the wine drinking experience. Flavour, 3(1). https://doi.org/10.1186/2044-7248-3-8

Srivastava, S., Donaldson, L. F., Rai, D., Melichar, J. K., \& Potokar, J. (2013). Single bright light exposure decreases sweet taste threshold in healthy volunteers. J Psychopharmacol, 27(10), 921-929.

Suwankanit, C., Dermiki, M., Kennedy, O.B., Methven, L. (2013). Umami: Suppressed by all other tastes but itself an enhancer of salty and sweet perception. Rio de Janeiro, Brazil: Poster presented at 10th Pangborn Sensory Science Symposium.

Veldhuizen, M. G., van Rooden, A. P., \& Kroeze, J. H. (2006). Dissociating pleasantness and intensity with quinine sulfate/sucrose mixtures in taste. Chemical Senses, 31(7), 649-653. https://doi.org/10.1093/chemse/bj1005

Vickers, Z., Holton, E., \& Wang, J. (2001). Effect of ideal-relative sweetness on yogurt consumption. Food Quality and Preference, 12(8), 521-526. https://doi.org/10.1016/ S0950-3293(01)00047-7

Walsh, V. (2003). A theory of magnitude: Common cortical metrices of time, space and quality. Trends in Cognitive Sciences, 7, 483-488. https://doi.org/10.1016/j. tics.2003.09.002

Wilson, G. D., \& Gregson, R. A. M. (1967). Effects of illumination on perceived intensity of acid tastes. Australian Journal of Psychology, 19(1), 69-73. https://doi.org/ $10.1080 / 00049536708255564$

Xu, A. J., \& Labroo, A. A. (2014). Incandescent affect: Turning on the hot emotional system with bright light. Journal of Consumer Psychology, 24(2), 207-216. 